\title{
Long-term significance of gestational carbohydrate intolerance - A Longitudinal Study
}

\author{
A.G. Schranz ${ }^{1}$ \\ C. Savona-Ventura ${ }^{2}$
}

1. Diabetic Clinic, Department of Medicine, St. Luke's Teaching Hospital, MALTA

2. Diabetic Pregnancy Joint Clinic, Department of Obstetrics-Gynaecology, St. Luke's Teaching Hospital, MALTA

\section{SUMMARY}

Severe forms of GDM have been conclusively associated with significantly increased risk of developing DM later on in life. The long-term significance of GIGT has not yet been definitely elucidated. The study was set up to compare the present carbohydrate metabolism status and anthropomorphic characteristics of women of women diagnosed as suffering from abnormal carbohydrate tolerance during pregnancy eight years previously with those recorded as having normal glucose tolerance. The prevalence of present abnormal glucose tolerance was significantly higher in women who had been noted to have carbohydrate intolerance during their pregnancy, the prevalence depending on the gestational severity $(10.0 \%$ in normal glucose tolerance, $36.4 \%$ in borderline GIGT; $66.7 \%$ in GIGT). Women whose overweight or obese status persists or develops after their pregnancy were statistically more likely to develop abnormal glucose tolerance later on in life (11.9-12.5\% in normal-overweight BMI, 38.2\% in obese BMI). A maternal and sibling, but not paternal, family history of diabetes was also a statistically significant risk factor. GIGT appears to be a definite risk factor for the development of carbohydrate metabolism problems later on in life, this being related to the severity during pregnancy and the presence or development of obesity. It is proposed that women diagnosed to suffer from GIGT should be regularly monitored after the pregnancy, particularly if other risk factors such as obesity are also present.

Keywords: diabetes mellitus, pregnancy, morbidity, risk factors

\section{INTRODUCTION}

It is generally accepted that the pregnancy-state with its diabetogenic character serves to bring to the forefront any latent tendency towards the development of diabetes later on in life. Several follow-up studies in various populations have concluded that gestational diabetes mellitus as defined by the 1985 WHO criteria is conclusively associated with significantly increased risk of development of DM later on in life, the risk being highest in women with an elevated fasting blood glucose (Kerenyi and Tamas, 1994). The long-term significance of minor degrees of gestational carbohydrate intolerance has not yet been definitely elucidated, though a number of studies have suggested that mild forms of carbohydrate intolerance during pregnancy may also be indicators of later risk (O'Sullivan, 1991).

The Maltese population in the Central Mediterranean has been repeatedly shown to have a high prevalence of carbohydrate metabolism problems, which is reflected in the pregnant population (Katona et al., 1983). The present study was set up to investigate the carbohydrate metabolism status and anthropomorphic characteristics of Maltese women who had been diagnosed eight years previously to suffer from GIGT. 


\section{MATERIAL AND METHODS}

Two hundred and sixty-nine women (269) were metabolically assessed during pregnancy in a randomised study during Jan-Oct 1985. An attempt was made to trace and recall this population for reassessment eight years later during Jan-Jun 1993. Of the 116 women [43.1\% of the original population] who responded, there appeared to be a bias towards those women who had some form of abnormality during pregnancy. The diagnostic classification for gestational abnormal glucose tolerance used during the index pregnancy was based on the 1985 WHO diagnostic criteria that included women with a blood glucose of 7.8$11.0 \mathrm{mmol} / \mathrm{l} 2$-hour post $75 \mathrm{~g}$ glucose load. To conform to the current diagnostic criteria, the study population during pregnancy was subdivided into three groups: normal glucose tolerance [NGT: 2-hour value $<7.8$ $\mathrm{mmol} / \mathrm{l}$ ], borderline tolerance [borderline GIGT: 2-hour value $7.8-8.5 \mathrm{mmol} / \mathrm{l}$, and impaired tolerance [GIGT: 2hour value $8.6-11.0 \mathrm{mmol} / \mathrm{l}$. The mean age of these women was $28.7 \pm 5.32$ years. None of the women in the study had required insulin treatment during their pregnancy. The non-pregnant diagnostic criteria for the $75 \mathrm{~g}$ oGTT used identified impaired glucose tolerance and diabetes mellitus with a 2-hour glucose value of 7.811.0 and $>11.0 \mathrm{mmol} / \mathrm{l}$ respectively, with any 2-hour post-glucose load value $>7.8 \mathrm{mmmol} / \mathrm{l}$ being considered abnormal glucose tolerance.

The anthropomorphic characteristics of the women were assessed using BMI and waist-hip ratios. Statistical analysis were made using the chi square test comparing women found to have carbohydrate intolerance during the non-pregnant state with those having a normal glucose tolerance at follow-up using a standard statistical package MedCalc (1993-97).

\section{RESULTS}

The prevalence of abnormal glucose tolerance was significantly higher in women who had been noted to have carbohydrate intolerance during their pregnancy, the prevalence depending on the gestational severity. Thus women whose gestational metabolic status had been established as normal had a present abnormal glucose tolerance prevalence of $10.0 \%$. In contrast those women whose gestational status had been established as borderline GIGT or GIGT now had a prevalence of $36.4 \%$ and $66.7 \%$ respectively (Table 1 ). The differences were statistically significant for both the borderline $(p=0.0477)$ and the GIGT group $(p<0.0001)$ suggesting a strong correlation between gestational status and subsequent risk of developing carbohydrate intolerance. Furthermore the severity of the present carbohydrate intolerance appeared to also be dependent on the gestational status. A present diagnosis of diabetes mellitus was made in $5.6 \%$ of women with a previously normal carbohydrate tolerance during pregnancy. There were no present cases of diabetes in women with borderline GIGT. In contrast a diagnosis of diabetes was made in $53.3 \%$ of women with a previous history of GIGT.

\begin{tabular}{|c|c|c|c|c|}
\hline \multirow[t]{2}{*}{ Pregnancy status } & \multicolumn{4}{|c|}{ Present Metabolic Status } \\
\hline & Normal & IGT & DM & $\begin{array}{c}\% \\
\text { abnormal } \\
\text { glucose } \\
\text { tolerance }\end{array}$ \\
\hline Normal glucose tolerance & 81 & 4 & 5 & 10.0 \\
\hline Borderline GIGT & 7 & 4 & 0 & 36.4 \\
\hline $\begin{array}{l}\text { GIGT } \\
\text { 2-hour value 8.6-11.0 }\end{array}$ & 5 & 2 & 8 & 66.7 \\
\hline
\end{tabular}

Table 1: Previous gestational metabolic status $[p<0.0001]$

Obesity during pregnancy as determined by BMI did not appear to have any statistical risk for the development of subsequent glucose intolerance (Table 2). Thus the prevalence of follow-up abnormal glucose tolerance was estimated as $17.0 \%$ in women whose gestational BMI was within the normal range and $22.2 \%$ in women whose gestational BMI was in the overweight-obese range $(p=0.6415)$. In the follow-up period, obesity as determined by both a high BMI $(p=0.0344)$ and an elevated waist-hip ratio $(p=0.0364)$ was however statistically correlated to a present abnormal glucose tolerance (Table 3 ). Hypertension was also statistically $(p=0.0188)$ associated with an increased prevalence of abnormal glucose tolerance (Table 3 ). Family history was similarly associated with an increased risk of developing abnormal glucose tolerance (Table 4), this being statistically significant with a maternal $(p=0.0018)$ or sibling $(p=0.041)$ family history. A paternal family history showed no increased risks $(p=0.7967)$.

\begin{tabular}{|c|c|c|c|}
\hline Pregnancy status & \multicolumn{3}{|c|}{ Present Metabolic Status } \\
\hline $\begin{array}{c}\text { Body stature \& } \\
\text { Glucose tolerance }\end{array}$ & $\begin{array}{c}\text { Normal } \\
\text { Tolerance }\end{array}$ & $\begin{array}{l}\text { Abnormal } \\
\text { tolerance }\end{array}$ & $\begin{array}{c}\% \\
\text { abnormal } \\
\text { glucose } \\
\text { tolerance }\end{array}$ \\
\hline $\begin{array}{l}\text { Normal BMI } \\
\text { Normal glucose tolerance } \\
\text { 2-hour value }<7.8 \mathrm{mmol} / \mathrm{I} \\
\text { Abnormal tolerance } \\
\text { 2-hour value }>7.8 \mathrm{mmmol} / \mathrm{l}\end{array}$ & $\begin{array}{rr}44 & \\
& 38 \\
& 6\end{array}$ & $\begin{array}{l}4 \\
5\end{array}$ & $\begin{array}{l}17.0 \\
9.5\end{array}$ \\
\hline $\begin{array}{l}\text { Overweight-Obese BMI } \\
\text { Normal glucose tolerance } \\
\text { 2-hour value }<7.8 \mathrm{mmol} / \mathrm{I} \\
\text { Abnormal tolerance } \\
\text { 2-hour value }>7.8 \mathrm{mmmol} / \mathrm{I}\end{array}$ & $\begin{array}{ll}49 & \\
& 43 \\
& 6\end{array}$ & $\begin{array}{l}5 \\
9\end{array}$ & $\begin{array}{r}22.2 \\
10.4 \\
60.0\end{array}$ \\
\hline
\end{tabular}

Table 2: Pregnancy Body stature and metabolic status $[p=0.6415]$ 


\begin{tabular}{|c|c|c|c|c|}
\hline \multirow{2}{*}{$\begin{array}{c}\text { Present Characteristics } \\
\text { BMI }\end{array}$} & \multicolumn{3}{|c|}{$\begin{array}{l}\text { Present Metabolic Status } \\
\end{array}$} & \multirow[b]{2}{*}{ Significance } \\
\hline & $\begin{array}{c}\text { Normal } \\
\text { Tolerance } \\
2 \mathrm{hr} \text { value }<7.8 \mathrm{mmol} / \mathrm{I}\end{array}$ & $\begin{array}{c}\text { Abnormal } \\
\text { Tolerance } \\
2 \mathrm{hr} \text { value }>7.8 \mathrm{mmol} / \mathrm{I}\end{array}$ & $\begin{array}{l}\% \text { abnormal } \\
\text { glucose } \\
\text { tolerance }\end{array}$ & \\
\hline Normal: $<25$ & 35 & 5 & 12.5 & \multirow[b]{3}{*}{$p=0.0344$} \\
\hline Overweight: $25-29$ & 37 & 5 & 11.9 & \\
\hline Obese: $>30$ & 21 & 13 & 38.2 & \\
\hline \multicolumn{5}{|l|}{ Waist-Hip ratio } \\
\hline $0.69-0.81$ & 51 & 7 & 10.5 & \multirow[b]{3}{*}{$p=0.0364$} \\
\hline$\quad 0.82-0.85$ & 24 & 6 & 20.0 & \\
\hline$\quad 0.86-0.94$ & 16 & 10 & 38.5 & \\
\hline \multicolumn{5}{|l|}{ Blood Pressure } \\
\hline Normotensive & 87 & 17 & 16.4 & \multirow[b]{2}{*}{$p=0.0188$} \\
\hline Hypertensive $>160 / 90$ & 6 & 6 & 50.0 & \\
\hline
\end{tabular}

Table 3: Present Risk factors

\begin{tabular}{|l|c|c|c|c|}
\hline Family History & \multicolumn{3}{|c|}{ Present Metabolic Status } \\
\cline { 2 - 5 } & $\begin{array}{c}\text { Normal } \\
\text { Tolerance } \\
\text { 2hr value } \mathbf{2 7 . 8} \mathbf{~ m m o l / I}\end{array}$ & $\begin{array}{c}\text { Abnormal } \\
\text { Tolerance } \\
\text { 2hr value } \mathbf{> 7 . 8} \text { mmol/I }\end{array}$ & $\begin{array}{c}\text { \% abnormal glucose } \\
\text { tolerance }\end{array}$ & significance \\
\hline Maternal & 22 & 14 & 38.9 & $p=0.0018$ \\
\hline Paternal & 20 & 5 & 20.0 & $p=0.7967$ \\
\hline Sibling & 3 & 4 & 57.1 & $p=0.041$ \\
\hline
\end{tabular}

Table 4: Family history

\section{DISCUSSION}

A number of long-term follow-up studies in different populations have shown that women who exhibited carbohydrate intolerance during pregnancy had a greater likelihood of developing impairment of carbohydrate metabolism later on in life particularly if associated with obesity. Integration and comparison of these studies is fraught by diversity in population selection, diagnosis criteria and study designs. Women with gestational abnormal glucose tolerance followed up in Leningrad $0.25-6$ years after delivery were found to have a $44.2 \%$ prevalence of subsequent abnormal glucose tolerance in contrast to a prevalence of $5.3 \%$ in the control group (O'Sullivan, 1991). Similar findings were reported in a Danish population where women with dietary-treated gestational diabetes followed up 2-11 years postpartum had a subsequent abnormal glucose tolerance prevalence of $24.4 \%$ in contrast to $5.3 \%$ in controls. This observation was confirmed in subsequent studies on the same population that further showed nonobese glucose tolerant women with previous GDM to be characterised by the metabolic profile of NIDDM i.e. insulin resistance and impaired insulin secretion. (Damm et al., 1992; Damm, 1999). Similarly Swedish women with previous gestational diabetes followed up 34 years postpartum had a prevalence of abnormal glucose tolerance of $25.4 \%$ in contrast to $4.0 \%$ of controls (Persson et al., 1991). An increased predisposition towards developing NIDDM in women with a history of gestational DM was also demonstrated in Aboriginal women of the Sioux Lookout Zone (Mohamed and Dooley, 1998). The present study confirmed that mild forms of carbohydrate intolerance during pregnancy appear to be definite risk factors for the development of carbohydrate metabolism problems later on in life, this being related to the severity during pregnancy and the presence or development of obesity.
Pregnancy may thus be considered to be the "crystal ball" for looking into the future to assess the likelihood of developing impairment of carbohydrate metabolism later on in life.

In support of previous epidemiological studies carried out in the Maltese population (Katona et al., 1983; Schranz 1989), a maternal or sibling family history has been found to be a significant risk factor. No such statistically significant correlation has been identified with a paternal family history in any of the epidemiological studies performed in this population. The maternal, but not paternal, association suggests that whereas a familiar tendency definitely exists, this is probably not a purely genetic influence. The familiar association is more likely the product of the minor alterations that occur in the intrauterine millieur interieur of the infant of the mother with abnormal carbohydrate metabolism. The role of the altered intrauterine environment in the aetiology of NIDDM has been previously suggested by epidemiological studies in other populations. Most convincing are the studies on Pima Indians which have shown that, besides a genetic transmission, the diabetic intrauterine environment can also induce a diabetogenic tendency in the offspring (Pettit et al., 1988). The relationship has also been shown by experimental animal models (Aerts and Van Assche, 1979) and also in human studies (SavonaVentura and Schranz, in press).

Since impaired glucose tolerance during pregnancy has been definitely identified as a significant risk factor towards development of later NIDDM, particularly in the presence or development of obesity, it is proposed that women diagnosed to suffer from GIGT and GDM should be regularly monitored after the pregnancy to identify the development of this insidious disorder and its long-term 
complications. Furthermore these women should be suitably counselled and advised to control their body weight and reduce their risk of developing NIDDM. The use of dietary and pharmacological intervention in women identified as high risk for developing NIDDM because they had been identified as suffering from diabetes during their pregnancy has been demonstrated (Wein et al., 1999).

\section{REFERENCES}

Aerts L, Van Assche A: Is gestational diabetes an acquired condition? J Developmental Physiology 1: 219225, 1979

Damm P: Gestational diabetes mellitus and subsequent development of overt diabetes mellitus. Dan Med Bull 45(5):495-509, 1998

Damm P, Kuhl C, Bertelsen A, Molsted-Pederson I: Predictive factors for the development of diabetes in women with previous gestational diabetes mellitus. Am J Obstet Gynecol 167: 607-616, 1992

Katona G, Aganovic I, Vuscan V, Skrabalo Z: The National Diabetes Programme in Malta - Final Report Phases I \& II. WHO.NCD/OND/DIAB/83.2. +115p., WHO, Geneva, 1983

Kerenyi Z, Tamas G: Diabetes and Pregnancy. In: Williams R, Papez L, Fuller J. (eds.). Diabetes in Europe. pp.94-107, INSERM, London, 1994

Mohamed N, Dooley J: Gestational diabetes and subsequent development of NIDDM in aboriginal women of northwestern Ontario. Int $\mathrm{J}$ Circumpolar Health 57(Suppl 1):355-8, 1998

O'Sullivan JB: Diabetes mellitus after gestational diabetes mellitus. Diabetes 29 (suppl.2): 131-135, 1991

Persson B, Hanson V, Hartling SG, Binder C: Follow-up of women with previous gestational diabetes mellitus: insulin, C-peptide and proinsulin responses to oral glucose load. Diabetes 40 (suppl 2): 136-141, 1991

Pettitt DJ, Aleck KA, Baird HR, Carraher MJ , Bennett $\mathrm{PH}$ : Congenital susceptibility to NIDDM. Role of intrauterine environment. Diabetes 37:622-628, 1988

Savona-Ventura C, Schranz AG: Metabolic effects of Infants born to mothers with G-IGT. A Pilot Study. Inter J Risk Safety Med, submitted

Schranz AG: Abnormal glucose tolerance in the Maltese. A population-based longitudinal study of the natural history of NIDDM and IGT in Malta. Diabetes Res Clin Pract 7: 7-16, 1989

WHO: Diabetes mellitus, report of a WHO study group. Technical report Series 727, WHO, Geneva, 1985

Wein $\mathrm{P}$, Beischer $\mathrm{N}$, Harris $\mathrm{C}$, Permezel M: A trial of simple versus intensified dietary modification for prevention of progression to diabetes mellitus in women with impaired glucose tolerance. Aust N Z J Obstet Gynaecol 39(2):162-6, 1999 